\title{
PENTINGNYA PENDOKUMENTASIAN YANG AKURAT DALAM KEPERAWATAN
}

\author{
EBIAL FITRI BR GINTING \\ ebyalfitriginting@gmail.com
}

\section{Latar Belakang}

Pendokumentasian yang akurat dan baikdalam asuhan keperawatan merupakan hal yang sangat penting, namun dalam prakteknya masih banyak hambatanhambatan yang mengakibatkan pendokumentasian yang dilakukan oleh perawat belum sempurna. Kurang patuhnya perawat akan berakibat rendahnya mutu asuhan keperawatan dan masih banyak lagi faktor-faktor yang mempengaruhi pelaksanaan pendokumentasian asuhan keperawatan.

Dengan terdapatnya kesadaran diri dari perawat maka akan meningkatkan motivasi perawat dalam melakukan pendokumentasian asuhan keperawatan. Dengan motivasi diri yang tinggi dan kepatuhan dari seorang perawat maka pencapaian tujuan akan pelaksanaan dokumentasi asuhan keperawatan akan dilakukan dengan baik dan meningkatkan pelayanan yang berkualitas dan profesional dalam bidang keperawatan,sehingga perawat perlu memiliki motivasi yang tinggi ketika melakukan pendokumentasian agar dapat memberikan hasil dari dokumentasi keperawatan yang baik.

Keperawatan adalah bentuk pelayanan profesional berupa pemenuhan kebutuhan dasar yang diberikan kepada individu yang sehat maupun sakit yang mengalami gangguan fisik, psikis, dan sosial agar dapat mencapai derajat kesehatan yang optimal. Bentuk pemenuhan dasar dapat berupa meningkatkan kemampuan yang ada pada individu, mencegah, memperbaiki, dan melakukan rehabilitasi dari suatu keadaan yang dipersepsikan sakit oleh individu.

Keperawatan merupakan bagian integral yang tidak dapat dipisahkan dari upaya 
pelayanan kesehatan secara keseluruhan. Keperawatan adalah ilmu yang mempelajari sebab-sebab tidak terpenuhinya kebutuhan dasar manusia, serta upaya untuk memenuhi kebutuhan dasar tersebut sebagai respon pasien. Pelayanan keperawatan profesional yang berdasarkan ilmu pengetahuan mempunyai proses keperawatan yaitu suatu asuhan keperawatan sebagai metode ilmiah penyelesaian masalah keperawatan pasien untuk meningkatkan outcome pasien yang harus didokumentasikan

Pendokumentasian asuhan keperawatan adalah kegiatan pencatatan, pelaporan dan pemeliharaan yang berkaitan dengan pengelolaan klien guna mempertahankan sejumlah fakta dari suatu kejadian dalam suatu waktu.

Dokumentasi adalah bukti pencatatan dan pelaporan yang dimiliki perawat dalam catatan yang berguna untuk kepentingan klien, perawat dan tim kesehatan dalam memberikan pelayanan kesehatan dengan dasar data yang akurat dan lengkap secara tertulis sebagai tanggung jawab perawat. Pelaksanaan dokumentasi keperawatan sebagai salah satu alat ukur untuk mengetahui, memantau dan menyimpulkan suatu pelayanan asuhan keperawatan yang diselenggarakan di rumah sakit.

Metode

metode yang digunakan oleh penulis adalah Literature review dengan cara menganalisis, kajian dan eksplorasi jurnal, text book, maupun e-book yang relevan dan membahas evaluasi asuhan keperawatan pada pasien lanjut usia Adapun jurnal yang digunakan pada literature review ini adalah jurnal yang diterbitkan dari kurun waktu 10 tahun terakhir didapatkan dengan menggunakan 2 database Portal Garuda dan Google Scholar.

Dalam melakukan dokumentasi oleh perawat Faktor tenaga dan motivasi merupakan faktor yang paling dominan yang mempengaruhi pendokumentasian asuhan keperawatan. Semakin tenaga tidak memadai dan motivasi yang tidak ada akan menurunkan kualitas asuhan keperawatan yang diberikan oleh perawat.

Hasil

Dalam melakukan dokumentasi oleh perawat Faktor tenaga dan motivasi 
merupakan faktor yang paling dominan yang mempengaruhi pendokumentasian asuhan keperawatan. Semakin tenaga tidak memadai dan motivasi yang tidak ada akan menurunkan kualitas asuhan keperawatan yang diberikan oleh perawat.

Pencatatan proses keperawatan merupakan metode yang tepat umtuk pengambilan keputusan yang sistematis, problem solving, dan riset lebih lanjut. Dokumentasi proses keperawatan mencakup pengkajian, identifikasi masalah, perencanaan, dan tindakan. Perawat kemudian Mengobservasi dan mengevaluasi respon klien terhadap tindakan yang diberikan, dan mengkomunikasikan informasi tersebut kepada tenaga kesehatan lainnya.

Perawat memerlukan suatu keterampilan untuk memenuhi standar pendokumentasian. Standar pendokumentasian adalah suatu pernyataan tentang kualitas dan kwantitas dokumentasi yang dipertimbangkan secara adekuat dalam situasi tertentu, berguna untuk memperkuat pola pencatatan dan sebagai petunjuk atau pedoman pendokumentasian dalam memberikan tindakan keperawatan.

Pembahasan

Dokumentasi keperawatan yang lengkap dan akurat akan memudahkan disiplin ilmun lain untuk menggunakan informasi di dalamnya. Dokumentasi diperlukan untuk memudahkan alur dan koordinasi dalam peraatan pasien.

Dokumentasi keperawatan yang akurat dan lengkap adalah sesuatu yang penting ketika berhadapan dengan pembayaran,dan kualitas pelayanan menuliskan bahwa perawat merasakan bahwa dokumentasi tertulis mereka tidak dihargai termasuk komunikasi verbal dengan profesi lain, karena komunikasi lisan yang yang tidak tertulis pada dokumentasi juga tidak dibayar.

Dokumentasi keperawatan merupakan bukti pencatatan dan pelaporan yang ditulis oleh perawatmengenai status dan kondisi klien dan digunakan sebagai alat komunikasi yang akurat dan lengkap. Sekarang ini perawat tidak hanya dituntut untuk meningkatkan kualitas asuhan keperawatan tetapi juga dituntut untuk dapat mendokumentasikan secara benar dan baik 
Tujuan Pendokumentasian yang dilakukan oleh perawat antara lain untuk :

1. Mengkomunikasikan data klien ke semua anggota tim kesehatan sehingga tidak terjadi data yang tumpang tindih dan salah dalam memberikan asuhan keperawatan.

2. Sebagai bukti-bukti untuk tujuan evaluasi hasil dari implementasi asuhan keperawatan

3. Untuk jaminan kepada masyarakat tentang lingkup dan mutu pelayanan keperawatan dan membuktikan pekerjaan perawatan serta meningkatkan tanggung gugat perawat.

4. Sebagai sumber data untuk melakukan penelitian. manfaat dari dokumentasi keperawatan adalah dimana dokumentasi keperawatan yang berisi semua catatan tentang informasi klien

dan merupakan dokumentasi yang resmi yang bernilai hukum. ika perawat mengalami suatu masalah yang berhubungan dengan profesi keperawatan, dimana peran perawat sebagai pemberi jasa dan klien sebagai pengguna jasa maka dokumentasi sangat diperlukan.

Dokumentasi dapat dijadikan barang bukti di pengadilan sebagai bukti. Maka dari itu data klien harus di identifikasi secara lengkap, jelas dan objektif dan ditandatangani oleh perawat, nama jelas, tanggal, perlunya penulisan dengan jelas agar tidak menimbulkan salah interpretasi. Pencatatan data klien yang dilakukan dengan lengkap dan akurat akan memberikan kemudahan bagi perawat dalam membantu menyelesaikan masalah yang dialami oleh klien. Selain itu untuk mengetahui sejauh mana masalah yang dialami oleh klien untuk dapat diatasi dan seberapa jauh masalah baru dapat di identifikasi dan di monitor melalui catatan yang akurat, hal ini akan membantu meningkatkan mutu keperawatan. Dokumentasi keperawatan adalah sebuah alat perekam terhadap masalah yang berkaitan dengan klien. Perawat atau tenaga kesehatan lain akan bisa melihat catatan yang ada dan sebagai alat komunikasi yang dijadikan pedoman dalam pemberian asuhan keperawatan kepada klien.

Pendokumentasian keperawaratan merupakan salah satu indikator kinerja perawat dalam melaksanakan asuhan keperawatan bisa dilihat dari pelaksanaan 
pendokumentasian asuhan keperawatan. Tanpa dokumentasi keperawatan maka semua implementasi keperawatan yang telah dilakukan oleh perawat tidak mempunyai makna dalam hal tanggung jawab dan tanggung gugat

Pelayanan keperawatan dilaksanakan dengan suatu sistem atau pola kerja yang disebut dengan sistem penugasan. Sistem penugasan terdiri atas penugasan mandiri, fungsional, tim, modular dan primer. Sistem penugasan keperawatan tidak hanya menekan-kan proses tetapi juga hasil. Hasil yang diharapkan dari sistem penugasan antara lain kepuasan kerja perawat, kepuasan pasien, lama rawat pendek, pendokumentasian asuhan optimal.

Tiga faktor yang mempengaruhi kinerja perawat dalam pendokumentasian yaitu faktor karakteristik individu seperti pendidikan, umur, jenis kelamin,masa kerja dan pengetahuan, sedangkan faktor psikologi misalnya motivasi dan faktor organisasi

Dokumentasi keperawatan mempunyai makna yang penting dalam berbagai aspek, yaitu aspek kualitas pelayanan karena pendokumentasian memberi kemudahan dalam memberikan pelayanan dan penyelesaian masalah klien sebagai acuan evaluasi untuk meningkatkan mutu pelayanan, aspek komunikasi dan sebagai sarana komunikasi antara perawat dengan klien atau keluarga, tenaga kesehatan lain sehingga dapat membentuk suatu koordinasi yang baik dan tidak terjadi duplikasi yang tidak efektif dan efisien, aspek hukum sebagai dokumen resmi dan bernilai hukum atau legalitas dalam sistem pelayanan keperawatan sehingga apabila terjadi suatu masalah hukum maka dokumentasi dapat dijadikan sebagai barang bukti di pengadilan, aspek pendidikan dan pelatihan dokumentasi mempunyai nilai pendidikan karena isinya menyangkut kronologis dari kegiatan asuhan keperawatan yang dapat dijadikan sebagai referensi pembelajaran bagi peserta didik profesi keperawatan, aspek keuangan semua asuhan keperawatan yang belum, sedang atau telah diberikan didokumentasikan yang dapat dijadikan acuan atau pertimbangan biaya bagi klien, aspek penelitian dapat dijadikan sebagai bahan atau objek riset dan pengembangan profesi keperawatan,aspek akreditasi pendokumentasian asuhan keperawatan sebagai indikator dalam penilaian suatu pelayanan keperawatan dalam akreditasi rumah sakit. 
Salah satu idikator kinerja perawat dalam melaksanakan keperawatan bisa dilihat dari pelaksanaan pendokumentasian asuhan. Tanpa dokumentasi keperawatan maka semua implementasi keperawatan yang telah dilakukuan oleh perawat tidak mempunyai makna dalam hal tanggung jawab dan tanggung gugat.

Pendokumentasian yang akurat dan baikdalam asuhan keperawatan merupakan hal yang sangat penting, namun dalam prakteknya masih banyak hambatanhambatan yang mengakibatkan pendokumentasian yang dilakukan oleh perawat belum sempurna. Kurang patuhnya perawat akan berakibat rendahnya mutu asuhan keperawatan dan masih banyak lagi faktor-faktor yang mempengaruhi pelaksanaan pendokumentasian keperawatan.

Penutup

Pendokumentasian dalam proses keperawatan merupakan hal yang sangat penting, namun didalam prakteknya masih banyak ditemukan hambatan hambatan yang mengakibatkan pendokumentasian belum baik dan sempurna. Kurang patuhnya perawat akan berakibat terhadap rendahnya mutu asuhan keperawatan ,disarankan untuk dapat memperbaiki ketenagaan, mempertahankan dan meningkatkan motivasi perawat dalam melaksanakan pendokumentasian proses keperawatan agar proses pendokumentasian berjalan dengan baik .

Dokumentasi yang dilakukan oleh perawat memiliki fungsi sebagai bukti bagi perawat telah melakukan tindakan yang dilakukannya.

Daftar pustaka

- Supratman, Yuni Wulan Utami. (2009). PENDOKUMENTASIAN ASUHAN KEPERAWATAN DITINJAU DARI BEBAN KERJA PERAWAT. Berita Ilmu Keperawatan, Vol. 2 No. 1, Maret 2009: 7-12

- Yunartha, M. (2017). Pelaksanaan Pendokumentasian Asuhan Keperawatan di RS 
Jiwa Daerah Provinsi Jambi. Scientia Journal, 4(3), 265-272.

- Sari, D. P., \& Siwi, G. R. (2019). Hubungan Antara Pengetahuan Perawat Tentang Rekam Medis dan Dokumentasi Keperawatan Dengan Kelengkapan Pencatatan Dokumentasi Keperawatan di Klinik MTA Surakarta 2019. Infokes Journal, 9(1), 45-49.

- Pitoyo, J., Susilaningsih., \& Supriyanto, A, 2003, Hubungan beban kerja perawat dengan pelaksanaan pendidikan kesehatan di RSUD Dr.Saiful Anwar Malang. Jurnal Kesehatan Politeknik Kesehatan Malang; 1: 35-42.

- Kimalaha, N., Mahfud, M., \& Anggraini, A. N. (2019). Pengetahuan dan Beban Kerja Perawat Berhubungan Dengan Kelengkapan Pendokumentasian Asuhan Keperawatan di Bangsal Penyakit Dalam dan Bedah. Indonesian Journal of Hospital Administration, 1(2), 79-88.

- Rezkiki, F., Febrina, W., \& Anggraini, D. (2019). PENGARUH PELAKSANAAN PRE DAN POST CONFERENCE TERHADAP PENDOKUMENTASIAN ASUHAN KEPERAWATAN. Real in Nursing Journal, 2(1), 21-28.

- Syukur, A. (2018). HUBUNGAN BEBAN KERJA DENGAN DOKUMENTASI ASUHAN KEPERAWATAN. NERSPEDI A JOURNAL, 1(2), 164-171.

- Tuinman, A., de Greef, M. H., Krijnen, W. P., Paans, W., \& Roodbol, P. F. (2017). Accuracy of documentation in the nursing care plan in long-term institutional care. Geriatric nursing, 38(6), 578-583.

- Paans, W., \& Müller-Staub, M. (2015). Patients' care needs: Documentation analysis in general hospitals. International journal of nursing knowledge, 26(4), 178-186.

- Mykkänen, M., Miettinen, M., \& Saranto, K. (2016). Standardized Nursing Documentation Supports Evidence-Based Nursing Management. In Nursing Informatics (pp. 466-470). 
- Simamora, R. (2009). Dokumentasi Proses Keperawatan

- Simamora, R. H., Purba, J. M., Bukit, E. K., \&Nurbaiti, N. (2019). PenguatanPeranPerawatDalamPelaksanaanAsuhanKeperawatanMelaluiPelatiha nLayanan Prima. JPPM (JurnalPengabdian Dan PemberdayaanMasyarakat), 3(1), 25-31. 